\section{Leprosy in the Dominican Republic}

According to Dr. Guillermo Iliviera (Bol. Of. San. Panamer., 22, 987 ; 1943), medical superintendent of the National Leprosarium of the Dominican Republic, 212 cases of leprosy have been treated there during the period $1922-42$, or are still confined there. 142 were men and 70 women. There were 75 deaths and 23 births. 147 cases were from the southern zone, while 44 were from the northern zone ; the central area was practically free from the disease. Estimating the total number of lepers in the Republic both in and out of the leprosarium at 224, one obtains a ratio of one leper per 8,500 inhabitants, which is much lower than that of India (1 per 3,000) and Japan (1 per 1,000).

\section{Performance of Cable Terminations}

IN a paper read by D. B. Irvin before the Institution of Electrical Engineers in London on November 8, the performance, over the period of twelve years ended 1943, of the cable terminations on the British Grid system at voltages between $3 \cdot 3 \mathrm{kV}$. and $132 \mathrm{kV}$. is reviewed, and the causes of breakdown are examined. For the period under review, termination failures account for approximately 40 per cent of the total cable circuit faults and they are classified as follows: design 39, workmanship 2, design or workmanship 18, maintenance 9 , and system conditions 12. Failures on $6 \cdot 6,11$ and $33 \mathrm{kV}$. circuits predominate. The failures attributed to design and workmanship were mainly due to imperfect stress control, inadequate internal clearances, compound migration, and presence of moisture; the incidence of these is discussed in the paper. The fundamental characteristics required of a cable termination are: (a) ability to withstand the electrical stresses associated with normal and emergency conditions of the voltage of the system and the occasional highvoltage impulses to which it will be subjected in service; $(b)$ ability to carry the maximum rated current of the circuit and the maximum fault current of short duration to which the circuit is liable; (c) retention of its initial electrical and mechanical qualities without deterioration, during the statutory life of the cable circuit in which it is incorporated; and $(d)$ economic cost to the user. Sectional drawings are included showing improved designs of sealing ends for various sizes and types of cables for voltages ranging from $3 \cdot 3$ to $132 \mathrm{kV}$., and the salient features of these are discussed briefly.

\section{Design of A.C. Turbo.Generators}

Is a paper read by G. A. Juhlin on December 7, before the Institution of Electrical Engineers in London, on the standardization and design of A.C. turbo-type generators, the possibilities of complete unification of designs, an alternative of mechanical interchangeability, and the standardization of requirements, which is the first step in either of these directions, are considered in turn. The author discusses standardization of design, future development, and standardization of requirements, which latter is the really valuable part of the paper. The conclusions arrived at are that for both commercial and technical reasons complete unification of designs must be regarded as impracticable under present conditions, and it seems very doubtful whether the alternative of mechanical interchangeability would be feasible.

\section{Announcements}

Dr. F. W: Aston has been awarded the twentyfirst Duddell Medal of the Physical Society, in recognition of his invention and development of the mass spectrograph.

Prof. G. M. Bennetr, University professor of chemistry at King's College, London, since 1938, has been appointed Government chemist in succession to the late Sir John Fox.

The title of emeritus professor of geography in the University of London has been conferred upon Prof. E. G. R. Taylor, in recognition and appreciation of her distinguished services to the University and to her subject.

Following on the recent appointment of Prof. J. A. Scott Watson as chief education and advisory officer to the Ministry of Agriculture and Fisheries, the Minister, in preparation for the setting up of a National Agricultural Advisory Service, has appointed the following senior education and advisory officers as from January I: Mr. F. Rayns, Dr. W. K. Slater and Dr. H. V. Taylor. Mr. Rayns's appointment is on a part-time basis, and he will continue to act as director of the Norfolk Experimental Station, Sprowston. $\mathrm{He}$ is succeeded as executive officer to the Norfolk War Agricultural Executive Committee by Mr. J. C. Mann, who was deputy executive officer of the Committee.

THE Therapeutic Research Corporation has elected the following officers for the year 1945: chairman of Board of Directors, Lord Trent (Boots Pure Drug Co., Ltd.), in succession to Mr. H. Jepheott (Glaxo Laboratories, Ltd.); deputy chairman, Dr. F. H. Carr (The British Drug Houses, Ltd.); chairman of Research Panel, Mr. F. A. Robinson (Glaxo Laboratories, Ltd.), in succession to Dr. A. J. Ewins (May and Baker, Ltd.); deputy chairman, Dr. C. H. Kellaway (Welleome Foundation, Ltd.), in succession to Mr. F. A. Robinson (Glaxo Laboratories, Ltd.).

IN view of the importance which eivil air transport will assume after the War, the Council of the Institution of Civil Engineers has decided to form a sixth Engineering Division to be known as the "Air Transport Division", to deal with such aspects of air transport as airports (land and sea), airfields, operational buildings and facilities, hangars, and signalling and other appliances in connexion with safety in flying. Until such time as a fully constituted divisional board has been elected, Mr. M. G. J. McHaffie has been appointed chairman of a provisional board.

THE twenty-seventh election to Beit Fellowships for Scientific Research will take place on or about July 7, when not more than three fellowships will be awarded. Candidates may be of any nationality but must be of European descent by both parents; and must be of university degree standing. Forms of application and all information may be obtained, by letter only, addressed to the Registrar, Imperial College, South Kensington, London, S.W.7, to whom they must be returned on or before April 6 .

- At a meeting of the Physical Society to be held at the rooms of the Royal Society on January 19 at 5 p.m., a lecture on "Imperfections of Crystal Lattices as investigated by Study of X-Ray Diffuse Scattering" will be delivered by Dr. A. Guinier, of the Laboratoire d'Essais, Conservatoire National des Arts et Métiers, Paris. 